\title{
Distribution of Genets of Perenniporia subacida in Stands of Chamaecyparis obtusa (Japanese Cypress) Determined by AFLP Fingerprints and Somatic Incompatibility
}

\author{
Masanobu Tabata, Forestry and Forest Products Research Institute, Ibaraki 305-8687, Japan; Yoshihisa Suyama, \\ Tohoku University, Miyagi 989-6711, Japan; and Yasuhisa Abe, Nihon University, Kanagawa 252-8510, Japan
}

\begin{abstract}
Tabata, M., Suyama, Y., and Abe, Y. 2009. Distribution of genets of Perenniporia subacida in stands of Chamaecyparis obtusa (Japanese cypress) determined by AFLP fingerprints and somatic incompatibility. Plant Dis. 93:826-831.

The clonal structure of Perenniporia subacida, a wood-rotting basidiomycete, was studied in a 30-year-old stand (site A; 1 ha) and a 43-year-old stand (site B; 0.5 ha) of Chamaecyparis obtusa in northern Kagawa Prefecture, Japan. A total of 110 isolates from decayed trees, stumps, wooden fences, logs, and mycelial mats were analyzed by amplified fragment length polymorphism (AFLP) and somatic incompatibility test (SIT). The results of AFLP, which agreed with those of SIT, revealed that the P. subacida population consisted of at least 17 genets at site A and 6 genets at site B. Individual genets were found in 1 to 9 trees at site A and in 1 to 7 trees at site B. One particular genet had spread over a distance of $70 \mathrm{~m}$. Root contacts were observed among roots of decaying stumps and living trees at both sites. White mycelial mats were often found where roots made contact between stumps and neighboring trees. These results suggest that $P$. subacida spreads vegetatively over significant distances through root contacts.
\end{abstract}

Chamaecyparis obtusa (Siebolt \& Zucc.) Endl. (Japanese cypress, "hinoki" in Japanese) is extensively planted in Japan, from the warm-temperate to the cooltemperate zones. Hinoki is endemic to Japan and one of the most important tree species for construction, especially for timber frames of Japanese houses. Hinoki plantations represent about $23 \%$ of the artificial forest area, and butt rots are sometimes found in these plantations. Tinctoporellus epimiltinus (Berk. \& Broome) Ryvarden is one of the fungi that cause butt rot of hinoki in the Kyushu District of Japan (16,21). In 1997, butt rot was found at a hinoki plantation in Kagawa Prefecture where thinning operations had taken place. Afterward, Tabata et al. (32) conducted a field survey on butt rot, studied the causal fungus, and demonstrated that it was caused by Perenniporia subacida (Peck) Donk (Basidiomycota, Polyporales, Polyporaceae).

$P$. subacida is one of the most common and widespread polypores in Asia, Europe, and North America (27). In Asia, it has been found in Japan, Russia, and China $(1,3,41)$. The fungus occurs predominantly in cool-temperate zones $(1,9,27)$, although T. epimiltinus is widespread in warmtemperate and tropical zones $(9,14,28)$. It

Corresponding author: M. Tabata

E-mail: butter@ffpri.affrc.go.jp

Accepted for publication 30 April 2009.

doi:10.1094/PDIS-93-8-0826

(C) 2009 The American Phytopathological Society sometimes produces basidiocarps on the surface of decayed stumps, logs, or dead trees from summer to autumn. Basidiocarps are white to cream, resupinate, becoming widely effused, up to $10 \mathrm{~mm}$ thick; the surface is composed of small pores, 3 to 5 per $\mathrm{mm}$. Basidiospores are hyaline, ovoid to broadly ellipsoid, smooth, thinwalled, 4 to $6 \times 3$ to $5 \mu \mathrm{m}$. Anamorph of the fungus has not been known.

The fungus causes white stringy rot, mostly in dead conifers and occasionally in hardwoods, and butt rot in living trees $(4,9,11,22,32,38)$. The early stage of decay appears as a light brown stain. Later, small white pits develop and coalesce to form a mass of white spongy fibers. Black flecks sometimes appear in the white fibers (32). However, how the fungus attacks living trees has not been known. Closely planted trees are sometimes found to have been decayed by the fungus, but it is uncertain whether they were infected individually by spores or invaded by mycelia from adjacent decayed trees through root contacts. To clarify the situation, it is necessary to identify and distinguish genets of $P$. subacida in the wild. Individual genets have been identified in other root and butt rot fungi including Armillaria mellea (Vahl) P. Kumm. s. 1. (18), Heterobasidion annosum (Fr.) Bref. s. 1. $(8,19,35,36)$, and Phellinus noxius (Corner) G. Cunn. (12). These fungi can spread from one tree to an adjacent tree by vegetative growth of the mycelia through host root systems.

A variety of methods have been used to elucidate fungal population structures of basidiomycetous fungi that infect forest trees, including somatic incompatibility
$(2,12,17,20,31)$, isozyme profiles $(10,12$, 13,31), random amplified polymorphic DNA (RAPD) analysis (10,20), microsatellite $(15,40)$, and amplified fragment length polymorphism (AFLP) analysis (34). Somatic incompatibility tests (SIT) do not require marker development but may not distinguish closely related genotypes (17). Isozyme profiles are relatively easy to establish but tend to underestimate levels of polymorphisms (31). RAPD analysis is a fast and simple technique to examine polymorphisms but suffers from a lack reproducibility (10). Microsatellite markers are well known as powerful tools for population genetic studies; however, it is said that fungal microsatellites appeared harder to isolate and to exhibit fewer polymorphism than in other organisms (5). On the other hand, AFLP is a particularly useful marker when DNA is pure and from cultures, but it is a much more limited and challenging method when the fungi cannot be cultured.

In this study, we studied the distribution of $P$. subacida genets in two stands of hinoki using AFLP analysis and SIT. We evaluated the usefulness of AFLPs as genetic markers in $P$. subacida populations and clarified the population structure of $P$. subacida in these stands.

\section{MATERIALS AND METHODS}

Study site. The study was conducted in 30-year-old (site A) and 43-year-old (site B) stands of hinoki in northern Kagawa Prefecture, where Tabata et al. $(32,33)$ had reported the root rots. Site A formerly was a broad-leaved forest but was cleared and replaced by a hinoki plantation around 1923. Hinoki was harvested in 1964 through 1968 and replanted in 1969 at a density of 4,000 trees/ha. The site is located at an elevation of about $650 \mathrm{~m}$ at a slope of 10 to 21 degrees and has about 1 ha total area.

Site B is $40 \mathrm{~m}$ away from site A and formerly was a Pinus densiflora forest, cut and replanted with hinoki at a density of 3,500 trees/ha in 1958. It is at the same elevation as site A, located on a slope of 4 to 10 degrees, and covers about 0.5 ha.

In the area, the mean annual precipitation is about $1,200 \mathrm{~mm}$ and the average temperature is about $12^{\circ} \mathrm{C}$. The sites are covered by a moderately moist brown forest soil (drier subtype: $\mathrm{B}_{\mathrm{D}}(\mathrm{d})$ ) according to the Japanese forest soil classification system (7). The soil has a shallow topsoil (A 
horizon) with a thin litter layer, and a compact subsurface soil (B horizon) of heavy clayey texture. The subsurface soil is not well drained and not well aerated.

Field surveys. One hundred thirty-two of the 30-year-old trees and 131 of the 43year-old trees were cut in the summers (May to September) of 1999 and 2001, respectively. Cut trees were classified into trees with and without decay in the butt, and their locations in the 30-year-old and 43-year-old stands were plotted on a map. When decay was found in a tree, stem disks 2 to $3 \mathrm{~cm}$ thick were taken at $10 \mathrm{~cm}$ intervals from the bases to the heights where decay could no longer be detected. The heights of decay were examined.

Eighteen stumps of 30-year-old trees that had been cut in 1999 were randomly selected between October and December 2000, and 17 stumps of 43-year-old trees cut in 2001 were selected between October to December 2001. Their root systems were excavated by hand up to a $1.2 \mathrm{~m}$ radius around the base of the tree and dissected to ascertain whether any wounds were related to the root decay.

Roots were dug up for 11 living trees and 8 stumps in a small plot $\mathrm{A} 1(8 \times 8 \mathrm{~m})$ at site $\mathrm{A}$, and for 9 living trees and 2 stumps in a small plot B1 $(6 \times 6 \mathrm{~m})$ at site $\mathrm{B}$, to check for root contact with fungi and fungal colonization.

Isolation. To isolate fungal strains, pieces were taken from decayed stems and roots of cut trees, old stumps, wooden fences, and felled logs. White mycelial mats were also collected from stems and roots of cut and living trees. Isolation was conducted as described previously, and cultures were identified by their cultural characteristics (32). The cultures isolated from stumps, decayed wood, and mycelial mats were identified by morphological characteristics following Nobles (24) and Stalpers (30), and also by comparing them morphologically with cultures derived from basidiocarps of the fungus. All cultures showed the same characteristics: colonies are white to whitish cream, cottony to wooly, with growth 60 to $70 \mathrm{~mm}$ in radius at $25^{\circ} \mathrm{C}$ in 14 days; generative hyphae are 1 to $7 \mu \mathrm{m}$ wide, with clamps (dikaryon); skeletal hyphae are thickwalled, 1 to $2 \mu \mathrm{m}$ wide. As the characteristics were the same in all basidiomycetous cultures, they were considered to represent a single species. Ninety-six isolates from site A (K1 to 96, Table 1) were used both for AFLP analysis and SIT. SIT was also conducted using 109 isolates from site B (K116 to 224, Table 2) and 30 isolates from plots $A 1$ and B1 (K97 to $115, \mathrm{~K} 225$ to 235, Tables 1 and 2). Fourteen isolates were used for AFLP analysis from site B (K116, 152, 160, 168, 180, 182, 183, 185, 187, 190, 191, 207, 208, 212; Table 2). The isolates were stored at the Forestry and Forest Products Research Institute.
DNA extraction and AFLP procedure. AFLP analysis was conducted using 110 of the isolates described above. Mycelia were grown at $25^{\circ} \mathrm{C}$ for 2 to 3 weeks on potato dextrose agar (PDA) plates. Fresh mycelial mats were collected with a pestle and ground using a Mixer Mill MM300 (Qiagen). DNA was extracted using the DNeasy Plant Mini Kit (Qiagen).

AFLP analysis was conducted according to the protocol of Perkin-Elmer's AFLP microbial fingerprinting. In the preselective amplification step, we used the preselective primer without selective nucleotide $(M s e \mathrm{I}+0$ and EcoRI+0). In the selective amplification step, we used a pair of selective primers (MseI+AC and EcoRI+C) which were identified as the most informative and reliable during a preliminary investigation (data not shown). Because the selected primer pair produced more than 80 markers and the difference among genets was clear (see results), we decided to use only one pair of selective primers in this study. We conducted the restriction digestion, ligation of adaptors, preselective amplification, and selective amplification using an iCycler thermal cycler (Bio-Rad Laboratories). AFLP profiles were obtained with an ABI PRISM 310 Genetic Analyzer and the GeneScan Analysis software (Applied Biosystems), and were compared regarding the presence and intensity of fragments.

Table 1. Isolates of Perenniporia subacida used for amplified fragment length polymorphism (AFLP) and/or somatic incompatibility test (SIT) at site A ${ }^{\text {a }}$

\begin{tabular}{|c|c|c|c|c|c|c|c|c|c|c|c|}
\hline Isolate & Origin & Tree* & Isolate & Origin & Tree* & Isolate & Origin & Tree* & Isolate & Origin & Tree* \\
\hline $\mathrm{K} 1$ & $\mathrm{RB}$ & KA1 & K31 & $\mathrm{RB}$ & KA17 & K61 & FA & & K91 & SA & KA56 \\
\hline $\mathrm{K} 2$ & BA & & K32 & SA & KA18 & K62 & BA & & K92 & SA & KA57 \\
\hline K3 & SA & KA2 & K33 & FA & & K63 & SA & KA35 & K93 & RA & KA58 \\
\hline K4 & SA & KA3 & K34 & $\mathrm{RB}$ & KA19 & K64 & SA & KA36 & K94 & LA & \\
\hline K5 & SA & KA4 & K35 & FA & & K65 & FA & & K95 & BA & \\
\hline K6 & FA & & K36 & SA & KA20 & K66 & SA & KA37 & K96 & $\mathrm{RB}$ & KA59 \\
\hline K7 & FA & & K37 & SA & KA21 & K67 & $\mathrm{RB}$ & KA38 & K97 & MB & KA60 \\
\hline K8 & FA & & K38 & SA & KA22 & K68 & SA & KA39 & K98 & BA & \\
\hline K9 & FA & & K39 & SA & KA23 & K69 & $\mathrm{RB}$ & KA40 & K99 & MB & KA61 \\
\hline K10 & SA & KA5 & K40 & SA & KA24 & K70 & SA & KA41 & K100 & BA & \\
\hline K11 & SA & KA6 & K41 & MA & KA25 & K71 & BA & & K101 & BA & \\
\hline K12 & $\mathrm{RB}$ & KA7 & K42 & BA & & K72 & SA & KA42 & K102 & BA & \\
\hline K13 & SA & KA8 & K43 & $\mathrm{RB}$ & KA26 & K73 & FA & & K103 & MB & KA62 \\
\hline K14 & RB & KA9 & K44 & BA & & K74 & $\mathrm{RB}$ & KA43 & K104 & MB & KA63 \\
\hline K15 & SA & KA9 & K45 & $\mathrm{RB}$ & KA27 & K75 & SA & KA44 & K105 & $\mathrm{MB}$ & KA64 \\
\hline K16 & SA & KA9 & K46 & $\mathrm{RB}$ & KA27 & K76 & RA & KA44 & K106 & BA & \\
\hline K17 & SA & KA9 & K47 & SA & KA28 & K77 & SA & KA45 & K107 & BA & \\
\hline K18 & $\mathrm{BA}$ & & K48 & SA & KA29 & K78 & SA & KA46 & K108 & MB & KA65 \\
\hline K19 & $\mathrm{RB}$ & KA10 & K49 & BA & & K79 & RA & KA47 & K109 & MB & KA66 \\
\hline K20 & SA & KA11 & K50 & SA & KA30 & K80 & SA & KA48 & K110 & BA & \\
\hline K21 & SA & KA12 & K51 & BA & & K81 & SA & KA49 & K111 & MB & KA67 \\
\hline K22 & BA & & K52 & RA & KA31 & K82 & LA & & K112 & MB & KA68 \\
\hline K23 & MA & KA13 & K53 & SA & KA32 & K83 & SA & KA50 & K113 & MB & KA69 \\
\hline K24 & SA & KA13 & K54 & SA & KA32 & K84 & SA & KA51 & K114 & BA & \\
\hline K25 & SA & KA13 & K55 & SA & KA32 & K85 & RA & KA52 & K115 & MB & KA70 \\
\hline K26 & SA & KA14 & K56 & SA & KA32 & K86 & SA & KA53 & & & \\
\hline K27 & MA & KA15 & K57 & LA & & K87 & BA & & & & \\
\hline K28 & BA & & K58 & SA & KA33 & K88 & SA & KA54 & & & \\
\hline K29 & BA & & K59 & RA & KA34 & K89 & SA & KA55 & & & \\
\hline K30 & SA & KA16 & K60 & FA & & K90 & BA & & & & \\
\hline
\end{tabular}

a Boxed isolates are from the same tree. BA: decayed old stump's root; FA: decayed wooden fence pole; LA: decayed log; MA: white mycelial mats formed on the bark of stem; MB: white mycelial mats formed on the bark of root; RA: P. subacida-infected root wounded by a small-size forwarder; RB: decayed root with unknown infection; SA: decayed stem from heights between 0.1 and $3.0 \mathrm{~m}$; Tree*: decayed tree number. 
Data analysis. Scores were determined as the presence of fragments (bands) in a reproducible range of fragment sizes. Dissimilarity of AFLP fingerprints between pairs of genets was calculated as $[b+c /(a$ $+b+c)$ ], where $a$ is the number of shared bands, and $b$ and $c$ are the numbers of bands present in one sample but absent in the other. These measures were subjected to UPGMA analysis using PHYLIP version $3.57 \mathrm{c}(6)$.

Mantel tests were performed to determine the correlation between the degree of polymorphism for a pair of genets and the shortest geographic distance at which two genets had been found. The test was performed using the web-based software developed by Rodney Dyer (http://dyerlab. bio.vcu.edu/cgi-bin/Mantel.cgi).

SIT. Two isolates were inoculated 2 to 3 $\mathrm{cm}$ apart on PDA plates in $9 \mathrm{~cm}$ petri dishes and incubated at $25^{\circ} \mathrm{C}$ in the dark for 2 to 3 weeks. We examined the presence or absence of a zone line between the isolates after 2 to 3 weeks of incubation. Self-pairings were also tested for each isolate. Two replicates were made for each combination.

\section{RESULTS}

Field surveys. After thinning, there were 2,000 trees/ha at site A and 1,200 trees/ha at site B. Butt rot was found in $58.3 \%$ of the felled trees at site A and in
$49.6 \%$ at site B. Decay was not found in the felled trees that were located between the spur road and the waterway (Fig. 1). The maximum height of rot was $3.0 \mathrm{~m}$ aboveground in the 30 -year-old trees. We collected 47 decayed stem disks from 41 trees at site $\mathrm{A}$ and 5 decayed stem disks from 5 trees at site B. Fifty-two samples of decayed stems were collected from heights of 0.1 to $3.0 \mathrm{~m}$.

Larvae of the root-feeding insect, Mimela costata Hope (larger striated chafer), sometimes were found on decaying roots on which they fed, leaving feeding wounds. Some roots apparently had been wounded by small-size forwarder used for carrying logs. Wounds were also caused by mutual root contacts or stones. Of the 112 decayed woody roots, 30 roots $(26.8 \%)$ showed wounds by mutual root contact, 28 $(25 \%)$ were by chafer larvae, $9(8 \%)$ by stones, $8(7.1 \%)$ by forwarder, and 37 $(33.1 \%)$ showed infections of unknown origin.

Old hinoki stumps cut in 1994 at sites A and $\mathrm{B}$ were found to be colonized by $P$. subacida (Tables 1 and 2). White mycelial mats were sometimes observed on the bark near the base of stems and on root bark of felled trees as well as living trees. They also spread from the roots of decayed stumps to those of adjacent living trees through root contact. However, no rhizomorph was found in the soil around the decayed stumps in the study sites. Basidiocarps of $P$. subacida were found on two of the stumps.

Wooden fences of hinoki, erected along the waterway to control erosion in 1995, were infected with $P$. subacida and decayed at site A. We found roots of infected trees to be in contact with the decayed fences. Some logs felled in 1996 had been left at site A. P. subacida grew on several of them and basidiocarps were found on a few of the decayed fallen logs.

Root contacts were observed between roots of living trees and decayed stumps in the small plots, A1 and B1. White mycelial mats were found on the surface of the roots of all living trees and decayed stumps in these plots, and were identified as $P$. subacida in culture studies.

Isolation. Three hundred and fifty isolates were taken from site $\mathrm{A}$ and 360 from site B; 235 isolates were selected for further study (Tables 1 and 2). The isolates were derived from 52 decayed stems and 112 decayed roots of felled trees, 29 decayed stumps, 10 decayed wooden fence poles, 3 decayed logs, and 29 white mycelial mats. They were identified as $P$. subacida by their morphological characteristics. Isolation rates of the fungus were 4.4 to $100 \%$ in decayed stems, 10 to $100 \%$ in roots, 30 to $100 \%$ in stumps, 11.1 to $100 \%$ in fences, 85.7 to $100 \%$ in fallen logs, and 28.6 to $90 \%$ in mycelial mats.

Table 2. Isolates of Perenniporia subacida used for amplified fragment length polymorphism (AFLP) and/or somatic incompatibility test (SIT) at the site Ba

\begin{tabular}{|c|c|c|c|c|c|c|c|c|c|c|c|}
\hline Isolate & Origin & Tree* & Isolate & Origin & Tree* & Isolate & Origin & Tree* & Isolate & Origin & Tree* \\
\hline K116 & RB & KB1 & K146 & $\mathrm{RC}$ & KB3 & K176 & RD & KB5 & K206 & $\mathrm{RB}$ & KB15 \\
\hline K117 & SA & KB2 & K147 & $\mathrm{RE}$ & KB3 & K177 & RD & KB5 & K207 & RB & KB16 \\
\hline K118 & MB & KB2 & K148 & $\mathrm{RB}$ & KB3 & K178 & RD & KB5 & K208 & BA & \\
\hline K119 & $\mathrm{RE}$ & KB2 & K149 & RE & KB3 & K179 & MB & KB6 & K209 & SA & KB17 \\
\hline K120 & RE & KB2 & K150 & RE & KB3 & K180 & $\mathrm{RE}$ & KB6 & K210 & $\mathrm{RB}$ & KB17 \\
\hline K121 & RE & KB2 & K151 & $\mathrm{RC}$ & KB3 & K181 & RE & KB6 & K211 & $\mathrm{RC}$ & KB17 \\
\hline K122 & $\mathrm{RC}$ & KB2 & K152 & $\mathrm{RE}$ & KB3 & K182 & SA & KB7 & K212 & $\mathrm{RC}$ & KB17 \\
\hline K123 & $\mathrm{RB}$ & KB2 & K153 & $\mathrm{RE}$ & KB3 & K183 & $\mathrm{BA}$ & & K213 & $\mathrm{RC}$ & KB17 \\
\hline K124 & $\mathrm{RE}$ & KB2 & K154 & MB & KB3 & K184 & $\mathrm{RC}$ & KB8 & K214 & $\mathrm{RB}$ & KB17 \\
\hline K125 & RB & KB2 & K155 & $\mathrm{RC}$ & KB3 & K185 & $\mathrm{RC}$ & KB8 & K215 & RD & KB17 \\
\hline K126 & RE & KB2 & K156 & $\mathrm{RC}$ & KB3 & K186 & BA & & K216 & $\mathrm{RB}$ & KB17 \\
\hline K127 & $\mathrm{RE}$ & KB2 & K157 & $\mathrm{RC}$ & KB3 & K187 & BA & & K217 & $\mathrm{RB}$ & KB17 \\
\hline K128 & RE & KB2 & K158 & $\mathrm{RC}$ & KB3 & K188 & $\mathrm{RC}$ & KB9 & K218 & RE & KB17 \\
\hline K129 & $\mathrm{RB}$ & KB2 & K159 & $\mathrm{RE}$ & KB3 & K189 & RB & KB10 & K219 & $\mathrm{RE}$ & KB17 \\
\hline K130 & $\mathrm{RE}$ & KB2 & K160 & MB & KB4 & K190 & $\mathrm{RB}$ & KB10 & K220 & $\mathrm{RC}$ & KB18 \\
\hline K131 & $\mathrm{RB}$ & KB2 & K161 & $\mathrm{RE}$ & KB4 & K191 & $\mathrm{RB}$ & KB11 & K221 & $\mathrm{RE}$ & KB18 \\
\hline K132 & $\mathrm{RC}$ & KB2 & K162 & $\mathrm{RE}$ & KB4 & K192 & RA & KB12 & K222 & $\mathrm{RE}$ & KB18 \\
\hline K133 & $\mathrm{RE}$ & KB2 & K163 & MB & KB5 & K193 & RA & KB12 & K223 & $\mathrm{RC}$ & KB18 \\
\hline K134 & $\mathrm{RE}$ & KB2 & K164 & $\mathrm{RE}$ & KB5 & K194 & $\mathrm{BA}$ & & K224 & $\mathrm{RC}$ & KB18 \\
\hline K135 & $\mathrm{RE}$ & KB2 & K165 & $\mathrm{RB}$ & KB5 & K195 & $\mathrm{RB}$ & KB13 & $\mathrm{K} 225$ & MB & $\overline{\text { KB19 }}$ \\
\hline K136 & $\mathrm{RE}$ & KB2 & K166 & $\mathrm{RE}$ & KB5 & K196 & SA & KB14 & K226 & MB & KB20 \\
\hline K137 & SA & KB3 & K167 & $\mathrm{RE}$ & KB5 & K197 & $\mathrm{RB}$ & KB14 & K227 & MB & KB21 \\
\hline K138 & $\mathrm{RC}$ & KB3 & K168 & RD & KB5 & K198 & $\mathrm{RC}$ & KB14 & K228 & MB & KB22 \\
\hline K139 & $\mathrm{RC}$ & KB3 & K169 & RD & KB5 & K199 & $\mathrm{RB}$ & KB14 & K229 & MB & KB23 \\
\hline K140 & $\mathrm{RC}$ & KB3 & K170 & $\mathrm{RC}$ & KB5 & K200 & $\mathrm{RB}$ & KB14 & K230 & MB & KB24 \\
\hline K141 & MB & KB3 & K171 & $\mathrm{RB}$ & KB5 & K201 & $\mathrm{RC}$ & KB14 & K231 & BA & \\
\hline K142 & $\mathrm{RC}$ & KB3 & K172 & RD & KB5 & K202 & $\mathrm{RB}$ & KB14 & K232 & MB & KB25 \\
\hline K143 & $\mathrm{RC}$ & KB3 & K173 & RD & KB5 & K203 & $\mathrm{RC}$ & KB14 & K233 & MB & KB26 \\
\hline K144 & $\mathrm{RC}$ & KB3 & K174 & RD & KB5 & K204 & $\mathrm{RB}$ & KB14 & K234 & MB & KB27 \\
\hline K145 & $\mathrm{RB}$ & KB3 & K175 & $\mathrm{RE}$ & KB5 & K205 & $\mathrm{RC}$ & KB14 & K235 & BA & \\
\hline
\end{tabular}

a Boxed isolates are from the same tree. BA: decayed old stump's root; MB: white mycelial mats formed on the bark of root; RA: $P$. subacida-infected root wounded by a small-size forwarder; RB: decayed root with unknown infection; RC: $P$. subacida-infected root wounded by larger striated chafer; RD: $P$. subacida-infected root wounded by the stone contact; RE: $P$. subacida-infected root wounded by mutual contact; SA: decayed stem from heights between 0.1 and $3.0 \mathrm{~m}$; Tree*: decayed tree number. 
AFLP analysis. Distinct AFLP fingerprints were obtained from the cultures. For the 96 samples collected at site A, a primer pair produced 33 to 45 (average 41 ) fragments per sample with sizes in the range of 50 to $300 \mathrm{bp}$. In total, 87 different fragments with lengths in this range were detected, $83 \%$ of which were polymorphic. We used these fragments to distinguish genetically distinct isolates. Seventeen groups were detected, and each group consisted of 1 to 19 isolates. Eight to 32 (average 21.9) fragments differed (were present/absent) when pairs of genets were compared, and 9.2 to $39.8 \%$ (average $25.2 \%$ ) of the fragments showed polymorphisms in these pairwise comparisons.

For the 14 samples collected from site $\mathrm{B}$, the primer pair produced 38 to 46 (average 41) 50 to $300 \mathrm{bp}$ fragments per sample in the range of 50 to $300 \mathrm{bp}$. In total, 87 such fragments were detected, and $77 \%$ were polymorphic. The fragments allowed us to define 6 groups of genetically distinct isolates; each group consisted of 1 to 3 isolates. In pairwise comparisons of genets, 13 to 24 (average 19.1) fragments differed (were present/absent) and 25.5 to $48 \%$ (average $37.9 \%$ ) of them showed polymorphisms.

Results of UPGMA analyses based on the dissimilarity of AFLP profiles in pairs of genets indicated few clearly defined genetic clusters of genets (Figs. 2 and 3). No significant correlation was found between the degree of polymorphism of each genet and the geographic distance to other genets by the Mantel test.
SIT. Clear zone lines indicating somatic incompatibility were formed in some pairings, while they were absent in others (suggesting somatic compatibility). The 96 isolates from site A were divided into 17 groups by SIT, in complete

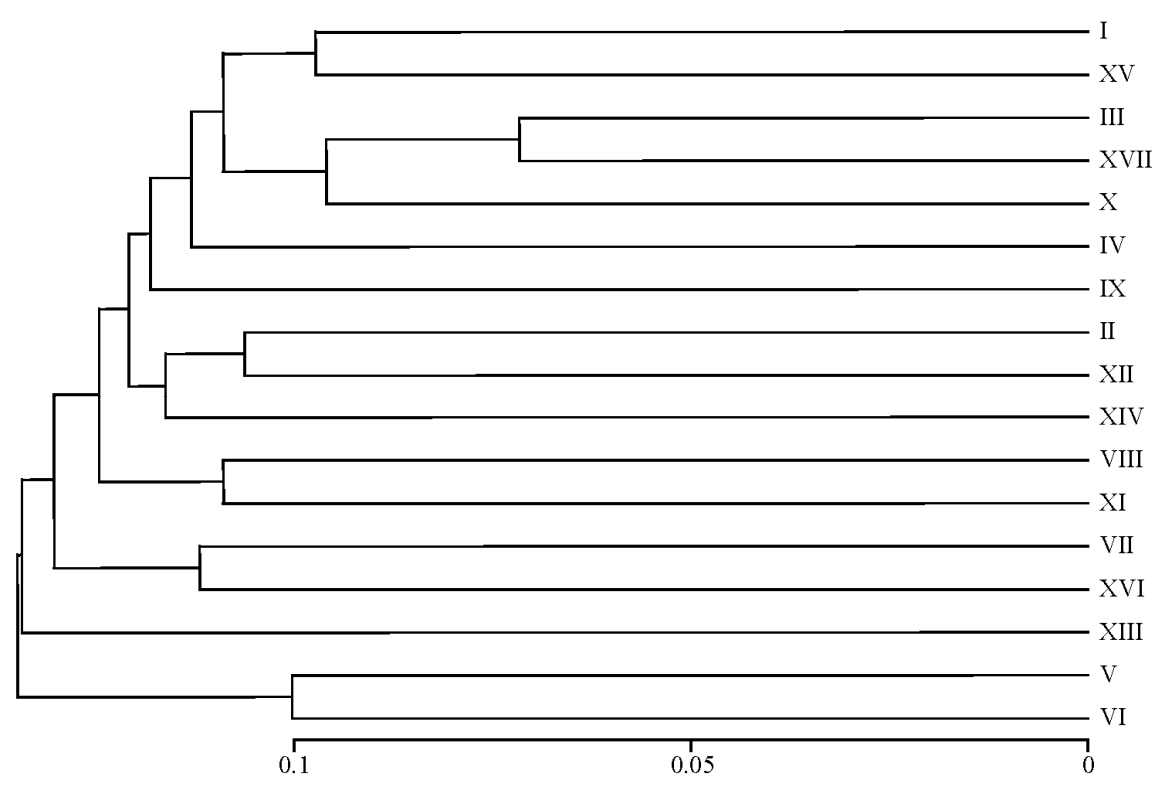

Fig. 2. UPGMA clustering based on dissimilarities of amplified fragment length polymorphism (AFLP) profiles of the 17 genets (I to XVII) of Perenniporia subacida at site A.

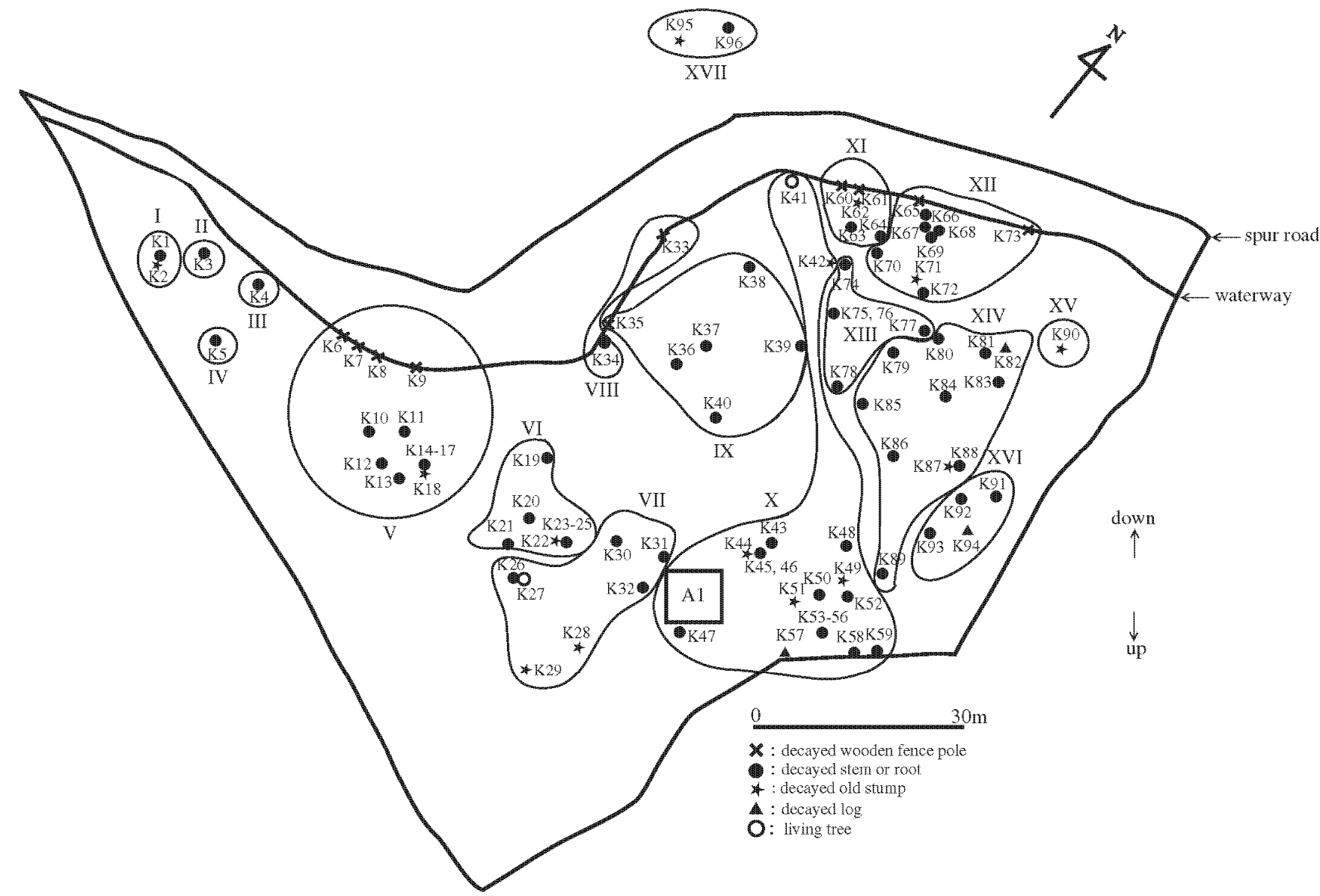

Fig. 1. Spatial distribution of 17 genets (I to XVII) of Perenniporia subacida inferred from amplified fragment length polymorphism (AFLP) fingerprints and somatic incompatibility test (SIT) of the isolates K1 to 96 at site A. 


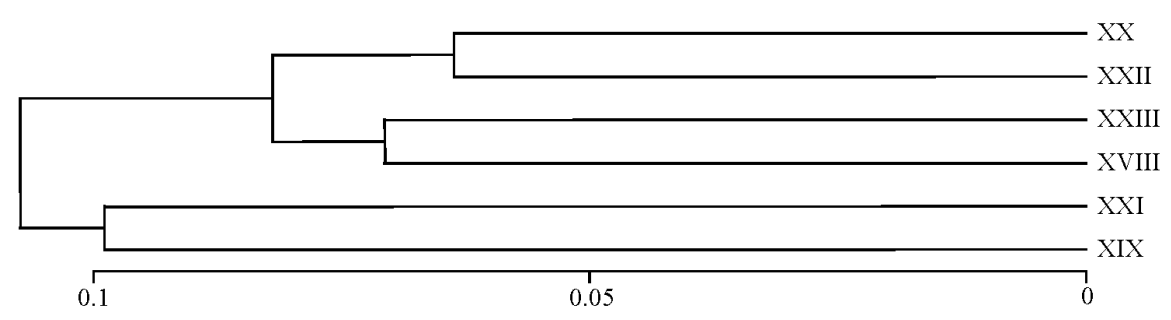

Fig. 3. UPGMA clustering based on dissimilarities of amplified fragment length polymorphism (AFLP) profiles of the 6 genets (XVIII to XXIII) of Perenniporia subacida at site B.
Al

0

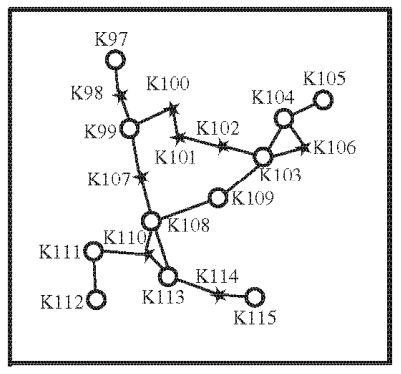

B1

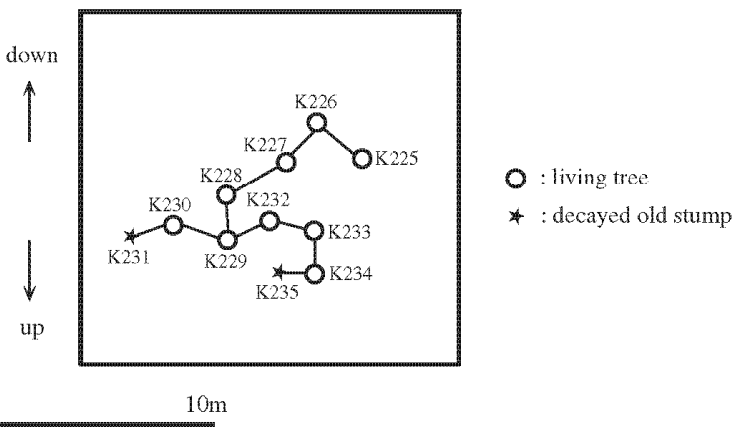

Fig. 4. Distribution of genets of Perenniporia subacida inferred from somatic incompatibility test (SIT) of isolates K97 to 115 in plot A1 and isolates K225 to 235 in plot B1, and root contacts between living trees and decayed stumps. Bars between trees and stumps indicate that the same genet of $P$. subacida had been found on both and that root contact between them had been observed.

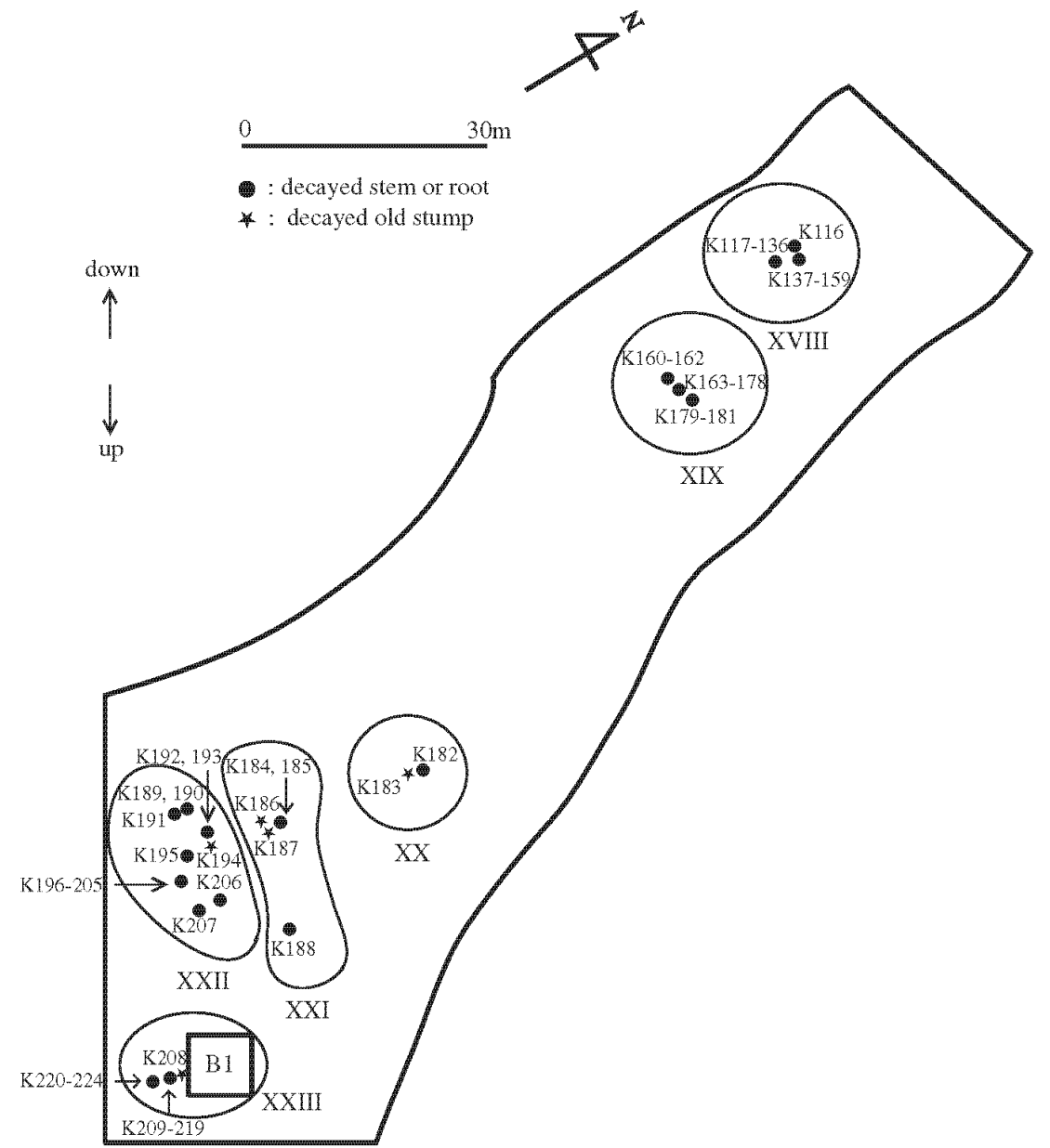

Fig. 5. Spatial distribution of 6 genets (XVIII to XXIII) of Perenniporia subacida inferred from amplified fragment length polymorphism (AFLP) fingerprints and/or somatic incompatibility test (SIT) of isolates $\mathrm{K} 116$ to 224 at site B. agreement with the results from AFLP analysis.

The 109 isolates from site B were divided into 6 groups by SIT; with respect to the 14 samples that had been analyzed by AFLP, there was a complete agreement between the results from AFLP and SIT. SIT also showed that the 19 isolates (K97 to 115) from plot $\mathrm{A} 1$ and the 11 isolates (K225 to 235) from plot B1 consisted of a single group each (X in Fig. 4A1 and XXIII in Fig. 4B1).

Spatial distribution of genets of $\boldsymbol{P}$. subacida. The spatial distribution of the 17 genets at site A is shown in Figure 1. Four genets were found only in one decayed tree or one decayed stump, while 13 genets were found in at least two places. One genet (XIV) was found in 9 trees and spread over a distance of $34.5 \mathrm{~m}$ (K81 and $\mathrm{K} 89$ ), while another genet (X) was found at locations more than $70 \mathrm{~m}$ apart (K41 and K58). The spatial distribution of the 6 genets at site B is shown in Figure 5. One genet (XXII) was found in 7 trees and another one (XXI) spread over a distance of $13.5 \mathrm{~m}$ (K184, K185, and K188). Same genets were sometimes isolated from decayed stumps and roots or stems of neighboring trees, for example $\mathrm{K} 1$ and $\mathrm{K} 2$ in the genet I, and K182 and K183 in the genet XXI (Figs. 1 and 5). Same genets were found in decayed wood fences and felled neighboring trees (genets V, VIII, XI, and XII). All isolates from roots and stems of the same trees were identical, for example K14 to 17 in the genet V (Fig. 1) and K117 to 136 in the genet XVIII (Fig. 5).

\section{DISCUSSION}

Butt rot caused by $P$. subacida was found in $54 \%$ of the hinoki trees felled by thinning activities at two sites, and was randomly distributed. No other species of wood-rot fungi like Tinctoporellus epimiltinus or Phaeolus schweinitzii were isolated from decaying wood in this area.

On the other hand, many genets were found in the population of $P$. subacida, 17 genets at site A and 6 genets at site B. A single genet was sometimes found in a single decayed tree or stump, but in other cases was found in more than two trees, nine different trees at maximum. There were at least 17 infection centers at site A from which the fungus appears to have spread by vegetative growth of mycelia. Root rot fungi are known to spread to neighbor trees by mycelial growth. Armillaria spp. often spread to neighboring trees by forming rhizomorphs $(25,26,29,39)$. On the other hand, Heterobasidion annosum, Phellinus noxius, and P. weirii do not produce rhizomorphs, but they spread via root contact of trees $(23,31,37)$. P. subacida does not produce any rhizomorphs in soil and appears to spread to neighboring trees by mycelial growth through root contacts.

The soil in the study sites was clay-rich, which means high dry bulk density and an 
air phase of low volume, leading to frequent occurrences of excess soil moisture (32). These soil properties seemed to promote the growth of the pathogen.

An analysis (Figs. 2 and 3) and the Mantel test based on the dissimilarity of AFLP profiles in pairs of genets indicated no significant correlation between the degrees of polymorphism and the locations where samples had been collected.

Decayed old stumps were present at most sites where genets of $P$. subacida were collected. Old stumps appear to be infection centers from which the fungus grows along the decaying root system, spreading to neighboring trees through root contacts $(32,33)$.

As wood fences were colonized by $P$. subacida and roots of neighboring trees came into contact with them, the fences appeared to be infection centers for neighboring trees. The fences had not been treated with preservatives, and their decay was more advanced than that in neighboring newly cut stumps. We suggest that wooden fences should not be used where root and butt rot damage exists.

Many types of wounds could occur in the root system of a single tree due to various causes such as root and stone contacts (33). It was expected that different genets of $P$. subacida would invade the same tree, however, only one genet was found per tree in every case. We assume that once a genet has invaded a tree through wounded roots, it spreads on the bark of the roots and prevents invasion by different genets. After colonization of a stump or tree, the fungus appears to spread to neighboring trees by vegetative growth of mycelia through root contacts.

The largest $P$. subacida genet spread up to $70 \mathrm{~m}$ in length (K41 and K58). This distance is similar to those found for $\mathrm{Ar}$ millaria spp. by Rishbeth (25) $(70 \mathrm{~m})$, Rizzo and Harrington (26) (35 m), Smith et al. (29) (70 m), Worrall (39) (40 m), for $H$. annosum by Stenlid (31) $(30 \mathrm{~m})$, and for Phellinus noxius by Hattori et al. (12) $(20 \mathrm{~m})$. The studies show that genets of these fungi may expand through root-toroot contacts or by rhizomorphs for more than several years, causing root and butt rot of conifers or hardwoods.

One genet $(\mathrm{X})$ was detected in isolated places more than $40 \mathrm{~m}$ apart (K42 and K48). Since many living trees and decayed stumps were present between the places where K42 and K48 were isolated, it is plausible that the infection spread through root contacts in living trees.

\section{LITERATURE CITED}

1. Aoshima, K. 1950. Wood-rotting Poria from Japan (I). (In Japanese, with English summary.) Bull. Gov. For. Exp. Stn. 46:155-168.
2. Barrett, D. K., and Uscuplic, M. 1971. The field distribution of interacting strains of Polyporus schweinitzii and their origin. New Phytol. 70:581-598.

3. Bondartsev, A. S. 1971. The Polyporaceae of the European USSR and Caucasia. (Translated from Russian.) Israel Program for Scientific Translations Ltd., Jerusalem.

4. Buckland, D. C. 1946. Investigation of decay in western red cedar in British Columbia. Can. J. Res. Sec. C. 24:158-181.

5. Dutech, C., Enjalbert, J., Fournier, E., Delmotte, F., Barres, B., Carlier, J., Tharreau, D., and Giraud, T. 2007. Challenges of microsatellite isolation in fungi. Fungal Genet. Biol. 44:933-949.

6. Felsenstein, J. 1995. PHYLIP (Phylogeny Inference Package) Ver. 3.57c. Department of Genetics, University of Washington, Seattle.

7. Forest Soil Division. 1976. Classification of forest soil in Japan (1975). Bull. Gov. For. Exp. Stn. Tokyo 280:1-28.

8. Garbelotto, M., Cobb, F. W., Bruns, T. D., Otrosina, W. J., Popenuck, T., and Slaughter, G. 1999. Genetic structure of Heterobasidion annosum in white fir mortality centers in California. Phytopathology 89:546-554.

9. Gilbertson, R. L., and Ryvarden, L. 1987. North American Polypores. Vol. 2. Fungiflora, Oslo.

10. Guillaumin, J. J., Anderson, J. B., Legrand, P., Ghahari, S., and Berthelay, S. 1996. A comparison of difference methods for the identification of genets of Armillaria spp. New Phytol. 133:333-343.

11. Hansen, E. M., and Lewis K. L. 1997. Compendium of Conifer Diseases. American Phytopathological Society, St. Paul, MN.

12. Hattori, T., Abe, Y., and Usugi, T. 1996. Distribution of clones of Phellinus noxius in a windbreak on Ishigaki Island. Eur. J. For. Pathol. 26:69-80.

13. Huttermann, A., Volger, C., Schorn, R., Ahnert, G., and Ganser, H. G. 1979. Studies on isoenzyme polymorphism in Fomes annosus. Eur. J. For. Pathol. 9:265-274

14. Ito, K. 1974. Pathology of forest trees III. (In Japanese.) Norin Shuppan, Tokyo.

15. Johannesson, H., and Stenlid, J. 2004. Nuclear reassortment between vegetative mycelia in natural populations of the basidiomycete Heterobasidion annosum. Fungal Genet. Biol. 41:563-570.

16. Katsu, Z. 1971. Butt rot of Chamaecyparis obtusa. (In Japanese.) For. Pests 20:141146.

17. Kile, G. A. 1983. Identification of genotypes and the clonal development of Armillaria luteobubalina Walting and Kile in eucalypt forests. Aust. J. Bot. 31: 657-671

18. Korhonen, K. 1978. Interfertility and clonal size in the Armillaria mellea complex. Karstenia 18:31-42.

19. Korhonen, K. 1978. Intersterility groups of Heterobasidon annosum. Commun. Inst. For. Fenn. 94(6):1-25

20. Kubayashi, T., and Hattori, T. 2002. Clone distribution of two causal fungi of root and butt rot in a Japanese cypress (Chamaecyparis obtusa) plantation. (In Japanese, with English summary.) J. Jpn. For. Soc. 84:104-110.

21. Kubayashi, T., Hattori, T., and Kawabe, Y. 2001. Tinctoporellus epimiltinus, a causal fungus of butt rot of Japanese cypress. For. Pathol. 31:43-52.

22. McCallum, A. W. 1928. Studies in forest pathology. I. Decay in balsam fir (Abies balsamea Mill.). Can. Dep. Agric. Bull. (n. s.)
104:1-25.

23. Nandris, D., Nicole, M., and Geiger, J. P. 1987. Root rot diseases of rubber trees. Plant Dis. 71:298-306.

24. Nobles, M. K. 1948. Studies in forest pathology. VI. Identification of cultures of woodrotting fungi. Can. J. Res. C. 26:281-431.

25. Rishbeth, J. 1991. Armillaria in an ancient broadleaved woodland. Eur. J. For. Pathol. 21:239-249.

26. Rizzo, D. M., and Harrington, T. C. 1993. Delineation and biology of clones of Armillaria ostoyae, A. gemina and A. calvesens. Mycologia 85:164-174.

27. Ryvarden, L., and Gilbertson, R. L. 1994. European Polypores Part 2: MeripilusTyromyces. Synopsis Fungorum 7:395-743.

28. Ryvarden, L., and Johansen, I. 1980. A preliminary polypore flora of East Africa. Fungiflora, Oslo.

29. Smith, M. L., Bruhn, J. N., and Anderson, J. B. 1994. Relatedness and spatial distribution of Armillaria genets infecting red pine seedlings. Phytopathology 84:822-829.

30. Stalpers, J. A. 1978. Identification of woodinhabiting Aphyllophorales in pure culture. Stud. Mycol. 16:1-248.

31. Stenlid, J. 1985. Population structure of Heterbasidion annosum as determined by somatic incompatibility, sexual incompatibility, and isoenzyme patterns. Can. J. Bot. 63:22682273.

32. Tabata, M., Kato, T., Ohkubo, M., Abe, Y., and Yoshinaga, S. 2002. Butt rot of Chamaecyparis obtusa (Sieb. et Zucc.) Endlicher trees caused by Perenniporia subacida in Shikoku District, Japan: Pathogen, distribution of damaged trees in the stand, and soil investigation. J. For. Res. 7:105-112.

33. Tabata, M., Takemoto, M., Toda, N., and Abe, Y. 2004. Infection of Perenniporia subacida in Chamaecyparis obtusa. Proc. 11th Int. Conf. Root Butt Rots. PoznanBialowieza, Poland.

34. Terashima, K., Cha, J. Y., and Miura, K. 2001. Detection of genetic variation among singlespore isolates and identification of genets of Armillaria ostoyae by AFLP analysis with Texas Red TM-labeled selective primer. Mycoscience 42:123-127.

35. Vasiliauskas, R., and Stenlid, J. 1998. Spread of $\mathrm{S}$ and $\mathrm{P}$ group isolates of Heterobasidion annosum within and among Picea abies trees in central Lithuania. Can. J. For. Res. 28:961966.

36. Vollbrecht, G., and Stenlid, J. 1999. Transfer of the P-type of Heterobasidion annosum from old-growth stumps of Picea abies to Picea abies and Larix $\times$ eurolepis. Eur. J. For. Pathol. 29:153-159.

37. Wallis, G. W., and Reynolds, G. 1965. The initiation and spread of Poria weirii root rot of Douglas fir. Can. J. Bot. 43:1-9.

38. Whitney, R. D. 1995. Root-rotting fungi in white spruce, black spruce, balsam fir in northern Ontario. Can. J. For. Res. 25:12091230.

39. Worrall, J. J. 1994. Population structure of Armillaria species in several forest types. Mycologia 86:401-407.

40. Worrall, J. J., Sullivan, K. F., Harrington, T. C., and Steimel, J. P. 2004. Incidence, host relations and population structure of Armillaria ostoyae in Colorado campgrounds. For. Ecol. Manag. 192:191-206.

41. Zhao, J. D. 1998. Flora Fungorum Sinicorum Vol. 3. Polyporaceae. (In Chinese.) Science Press, Beijing. 